OPEN ACCESS

Edited by:

Jon Fjeldså,

University of Copenhagen, Denmark

Reviewed by:

Mirko Di Febbraro,

University of Molise, Italy

Francesco Carotenuto,

University of Naples Federico II, Italy

*Correspondence:

Nils Chr. Stenseth

n.c.stenseth@mn.uio.no

${ }^{\dagger}$ These authors share first authorship

Specialty section:

This article was submitted to

Conservation and Restoration

Ecology,

a section of the journa

Frontiers in Ecology and Evolution

Received: 29 September 2020

Accepted: 24 June 2021

Published: 20 July 2021

Citation:

Gebremedhin B, Chala D, Flagstad Ø, Bekele A, Bakkestuen V, van Moorter B, Ficetola GF, Zimmermann NE, Brochmann C and Stenseth NC (2021) Quest for New

Space for Restricted Range Mammals: The Case of the

Endangered Walia Ibex.

Front. Ecol. Evol. 9:611632. doi: 10.3389/fevo.2021.611632

\section{Quest for New Space for Restricted Range Mammals: The Case of the Endangered Walia Ibex}

\author{
Berihun Gebremedhin ${ }^{1 \dagger}$, Desalegn Chala ${ }^{2 \dagger}$, Øystein Flagstad ${ }^{3 \dagger}$, Afework Bekele ${ }^{4}$, \\ Vegar Bakkestuen 2,5, Bram van Moorter ${ }^{3}$, G. Francesco Ficetola ${ }^{6,7}$, \\ Niklaus E. Zimmermann ${ }^{8}$, Christian Brochmann ${ }^{2}$ and Nils Chr. Stenseth ${ }^{1,4 *}$ \\ ${ }^{1}$ Department of Biosciences, Centre for Ecological and Evolutionary Synthesis (CEES), University of Oslo, Oslo, Norway, \\ ${ }^{2}$ Natural History Museum, University of Oslo, Oslo, Norway, ${ }^{3}$ Nonwegian Institute of Nature Research, Trondheim, Norway, \\ ${ }^{4}$ Department of Zoological Science, Addis Ababa University, Addis Ababa, Ethiopia, ${ }^{5}$ Norwegian Institute for Nature \\ Research, Oslo, Norway, ${ }^{6}$ Department of Environmental Sciences and Policy, Università degli Studi di Milano, Milan, Italy, \\ ${ }^{7}$ Laboratoire d'Écologie Alpine (LECA), Univ. Grenoble Alpes, CNRS, Grenoble, France, ${ }^{8}$ Swiss Federal Research Institute \\ WSL, Birmensdorf, Switzerland
}

Populations of large mammals have declined at alarming rates, especially in areas with intensified land use where species can only persist in small habitat fragments. To support conservation planning, we developed habitat suitability models for the Walia ibex (Capra walie), an endangered wild goat endemic to the Simen Mountains, Ethiopia. We calibrated several models that differ in statistical properties to estimate the spatial extent of suitable habitats of the Walia ibex in the Simen Mountains, as well as in other parts of the Ethiopian highlands to assess potentially suitable areas outside the current distribution range of the species. We further addressed the potential consequences of future climate change using a climate model with four emission scenarios. Model projections estimated the potential suitable habitat under current climate to 501$672 \mathrm{~km}^{2}$ in Simen and 6,251-7,732 km² in other Ethiopian mountains. Under projected climate change by 2,080 , the suitable habitat became larger in Simen but smaller in other parts of Ethiopia. The projected expansion in Simen is contrary to the general expectation of shrinking suitable habitats for high-elevation species under climate warming and may partly be due to the ruggedness of these particular mountains. The Walia ibex has a wide altitudinal range and is able to exploit very steep slopes, allowing it to track the expected vegetation shift to higher altitudes. However, this potential positive impact may not last long under continued climate warming, as the species will not have much more new space left to colonize. Our study indicates that the current distribution range can be substantially increased by reintroducing and/or translocating the species to other areas with suitable habitat. Indeed, to increase the viability and prospects for survival of this flagship species, we strongly recommend human-assisted reintroduction to other Ethiopian mountains. Emulating the successful reintroduction of the Alpine ibex that has spread from a single mountain in Italy to its historical ranges of the Alps in Europe might contribute to saving the Walia ibex from extinction.

Keywords: connectivity, corridors, endemic species, distribution range, habitat loss, habitat suitability modeling, reintroduction, translocation 


\section{INTRODUCTION}

There is increasing evidence that anthropogenic land use change poses imminent threats to biodiversity globally (Leadley, 2010; Watson et al., 2014). Indeed, humans have greatly altered the distribution ranges of endangered species and directly impacted their survival (Thuiller et al., 2005). Degradation of ecosystem services goes hand in hand with species extinctions, declining species abundances, and widespread shifts in species distributions (Leadley, 2010). The current rate of global extinction in biodiversity due to human activities is orders of magnitude higher than natural extinction rates (Pimm et al., 1995). Natural rates are calculated as approximately 1.8 extinctions per year per million species, whereas anthropogenic rates during the last 500 years have reached 28-100 extinctions per year per million species (Barnosky et al., 2011).

While land use change was considered the main driver of terrestrial biodiversity loss during the twenteith century, climate change is increasingly becoming a threat (Leadley, 2010). Climate change has started to impose multiple impacts on species, such as demographic and phenological changes, species range shifts and range size changes (Pounds et al., 1999; Bellard et al., 2012). Many species are shifting their ranges toward higher elevations and latitudes (Lenoir et al., 2008; Lovari et al., 2020), but migration is not always possible, because suitable areas can be lacking or because habitat loss has disrupted connectivity (Early and Sax, 2011). Given current trends, climate change could surpass habitat destruction as the greatest global threat to biodiversity over the coming decades (Leadley, 2010). The populations of large mammals have declined at alarming rates, especially in areas of intense land use where species can only persist in small habitat fragments, and often inside protected areas (Morrison et al., 2007). However, even protected areas face strong pressures from increasing human populations (McNeely, 1994). Hence, ensuring the survival of large mammals in human-dominated landscapes is challenging (Morrison et al., 2007; Gordon, 2009).

Modeling the suitability of habitats by means of species distribution models (SDMs) has become increasingly important to understand species ecology and develop conservation strategies (Morrison et al., 2007; Lobo et al., 2010), particularly to address the impact of climate change on species distributions (Araújo et al., 2004). SDMs assess the relationships between species occurrence data and environmental predictors to evaluate the suitability of a given area for a target species (Guisan and Zimmermann, 2000), and allow for identifying suitable areas for species conservation management (Zielinski et al., 2006; Thuiller, 2007). Multiple statistical algorithms are used for modeling species distributions. The combination of multiple models (ensemble forecasting) for suitability projections are a means to visualize uncertainty, thus providing more robust conclusions for conservation planning (Thuiller et al., 2006; Araújo and New, 2007; Marmion et al., 2009; Meller et al., 2014).

The Walia ibex (C. walie) is an endangered (EN) species restricted to the montane, sub-afro-alpine and afro-alpine habitats of the Simen Mountains in northern Ethiopia. It inhabits rugged and steep terrain in a single conservation area, the Simen Mountains National Park. The park was established as a direct response to the high conservation significance of the species. Main threats resulting in population decline of the Walia ibex originated from habitat loss due to agricultural expansion, overgrazing, constructions, and occasional poaching (Galvin and Haller, 2008). Low genetic variability, with an effective population size $\left(N_{\mathrm{e}}\right)$ much smaller than the census population size (Gebremedhin et al., 2009), is an additional threat. Genetic data have documented a past population bottleneck, which combined with its single small distribution area has led to extremely low genetic diversity; in fact, one of the lowest ever recorded in any endangered mammal species (Gebremedhin et al., 2009). The Walia ibex has the smallest current distribution of all wild goat species $\left(<100 \mathrm{~km}^{2}\right)$, but it had a much larger range, including mountains beyond the park boundary, in the past (Figure 1). However, anthropogenic factors pushed the population to the verge of extinction, with an estimated total population of 150 individuals in the early 1990's. Due to conservation measures, the population is recovering, and current estimates suggest a population size of $>957$ (Ejigu et al., 2017). Given this trend, the protected area may not have adequate suitable habitat to support a larger population in the future. Proposed conservation actions include the establishment of viable populations in other suitable areas, for instance by facilitating movements or through translocations to adjacent unoccupied habitats (Hirzel et al., 2002; IUCN, 2013). Such actions require the identification of suitable habitat area outside the current park boundaries (Seddon et al., 2007). SDMs allow for identifying such suitable areas, thereby supporting a detailed planning of translocations or assisted colonization of new habitats. Given that climate change will further modify the distribution of potentially suitable habitats in the future, such scenarios should additionally be taken into account in conservation management planning.

In this study, we analyzed and estimated the spatial extent of the suitable habitats of the Walia ibex in the Simen Mountains, and projected our models to other Ethiopian mountains to assess whether areas with potentially suitable bioclimatic conditions exist. Being a mountain specialist, we expect the ibex to be negatively affected by climate warming in all mountains due to shrinkage of its habitat. To test this hypothesis and in order to understand the spatiotemporal dynamics of suitable areas, we addressed the potential consequences of future climate change. We implemented three different strategies to improve the reliability of our species distribution predictions. Specifically, (i) when predicting models under present and projected future climate conditions, we excluded any territory where the models extrapolated; (ii) we accounted for imperfect detection of presences; and (iii) we measured habitat features that are indicative of an increase or decrease in total suitable areas under present and projected future conditions. Our results are discussed and evaluated in a conservation context.

\section{MATERIALS AND METHODS}

\section{Study Area}

The Simen Mountains National Park (with area of $412 \mathrm{~km}^{2}$ ), situated in northern Ethiopia at $13^{\circ} 9^{\prime} 57^{\prime \prime}-13^{\circ} 19^{\prime} 58^{\prime \prime}$ northern 
latitude and $37^{\circ} 54^{\prime} 48^{\prime \prime}-38^{\circ} 24^{\prime} 43^{\prime \prime}$ eastern longitude, is the only refuge for the Walia ibex (Figure 1). The park is topographically diverse with an elevation ranging from 1,900 to $4,543 \mathrm{~m}$ above sea level (a.s.l.). Agriculture is the dominant land use system. The natural vegetation is divided into three main zones: the montane forest belt, the transitional ericaceous belt, and the uppermost afro-alpine belt (Puff and Nemomissa, 2005).

\section{Occurrence Data}

The Walia ibex inhabits altitudes between 2,700 and 4,300 $\mathrm{m}$ a.s.l. (Ejigu et al., 2015), but historical data indicate that the species has inhabited altitudes as low as 2,300 $\mathrm{m}$ (Nievergelt, 1981). Here, we followed (Nievergelt, 1981) and considered all areas above 2,300 $\mathrm{m}$ in the Simen and in other Ethiopian mountains (Figure 1) as our study area.

The extant range of the Walia ibex is well known, and is the subject of regular monitoring (Gebremedhin et al., 2009, 2010). We performed repeated surveys of the Walia ibex habitats through the whole range of the species from March to April 2011. We used binoculars and telescopes to spot the animal from a distance. Presence points were recorded at the spot an individual or a group of Walia ibex were seen or fecal samples were observed. Individuals or groups of Walia ibex that were seen within less than about $100 \mathrm{~m}$ distance were considered as the same group. In such a way, we documented 214 occurrence points of Walia ibex.

\section{Predictor Variables}

Nineteen bioclimatic candidate variables at the 30 arc-seconds resolution (about $1 \mathrm{~km}^{2}$ ) were obtained from WorldClim (Hijmans et al., 2005). Slope and aspect were additionally derived from the $90 \mathrm{~m}$ resolution Shuttle Radar Topography Mission digital elevation model (SRTM DEM) (Jarvis et al., 2008). The elevation model was resampled by using the nearest neighbor resampling algorithm by means in Google Earth Engine (GEE) to the same resolution as the WordClim variables before derivation of slope and aspect. Aspect was kept as a continuous variable in the analyses. We used GlobCover (Arino et al., 2012), resampled to $1,000 \mathrm{~m}$ using the majority nearest neighbor resampling algorithm in GEE, to represent land cover. Each land cover class was converted to 0 and 1 by specifying each category data as a dummy variable.

To limit multicollinearity effects, we evaluated pairwise Pearson correlations among predictor variables, and selected only variables with $r<|0.7|$, selecting the ones with higher biological importance. We retained eight variables: slope angle, slope aspect, land cover, isothermality (BIO3), temperature annual range (BIO7), precipitation of the wettest month (BIO13), precipitation of the warmest month (BIO18) and precipitation of the coldest quarter (BIO19).

All models from the three algorithms were projected to all Ethiopian highlands (areas $>2,300 \mathrm{~m}$; Figure 1), both for current and projected future climates, using the same criteria as described above to assess suitability. We projected the models to future climates representing the year 2,080 using data from the Community Climate System Model version 4 (CCSM4) relying on all the four emission scenarios (RPCs 2.6, 4.5, 6.0, and 8.5 $\mathrm{Wm}^{2}$ of radiative forcing).

\section{Model Fitting and Evaluation}

Three statistical modeling approaches were applied, differing in general performance and statistical properties: (1) The Maximum Entropy Model (MaxEnt), a parametric maximum likelihood approach (Phillips et al., 2006; Halvorsen, 2013; Halvorsen et al., 2015); (2) The Generalized Additive Model (GAM), a nonparametric maximum likelihood approach (Wood, 2011); and (3)

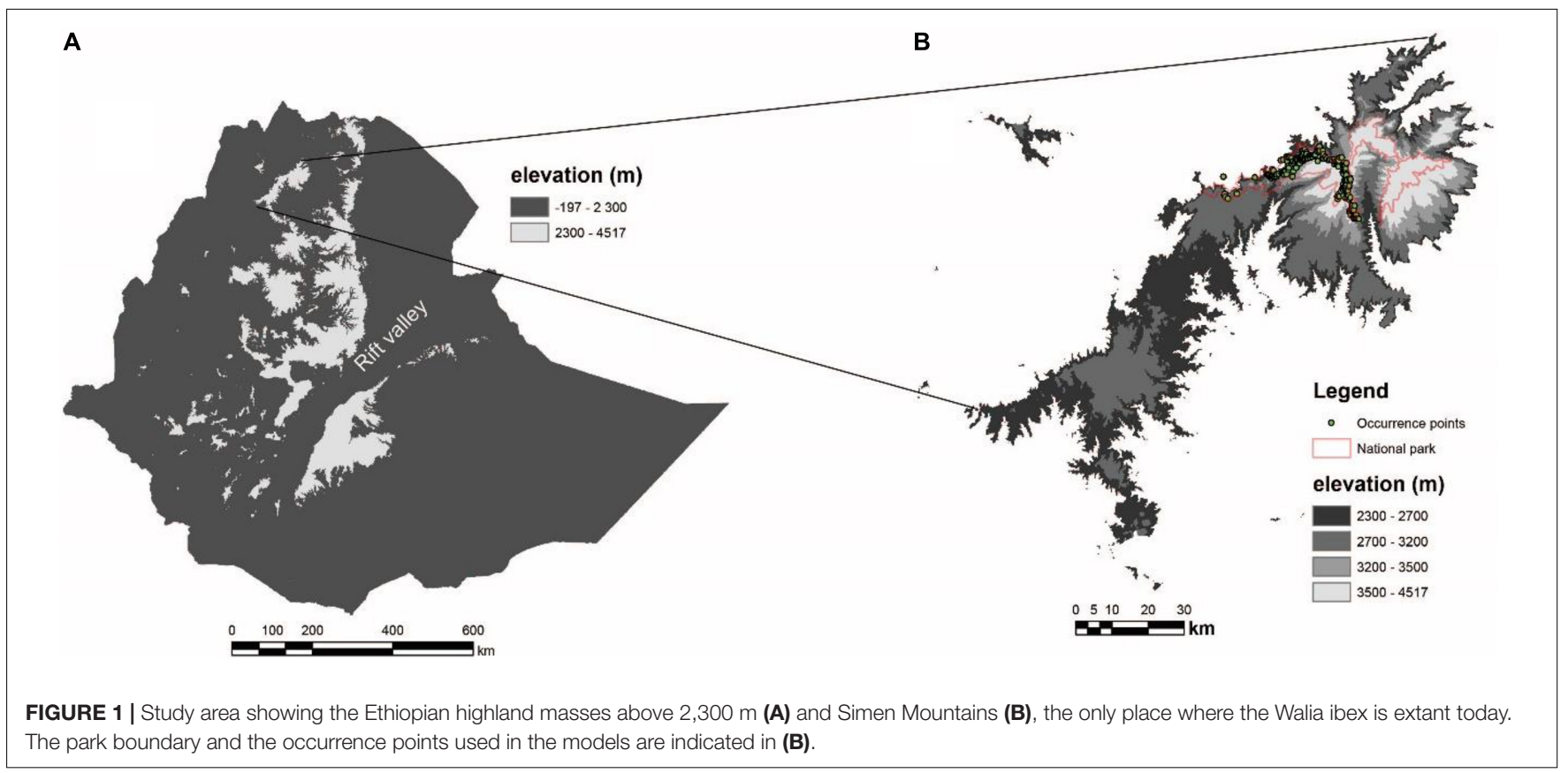


The Gradient Boosting Model (GBM), a resampling (boosting) approach (Friedman et al., 2000; Elith et al., 2008).

The different modeling approaches calls for different way of creating absence points (Barbet-Massin et al., 2012). For MaxEnt and GAM we used the thickening procedure proposed by Vollering et al. (2019a) for collection of absences (background points and pseudo-absences). We generated 10,000 weighted points within discrete thickening distances by analyzing geostatistical properties of the predictors such as semi-variance. The weighting was performed by using the relative probability of absences to be equal to the number of presences within a radius length of each location determined of the spatial-autocorrelation range of the predictor variables (Vollering et al., 2019b). A minimum separation distance was set to $10 \mathrm{~km}$. In the third algorithm (GBM), we randomly generated pseudo-absence points equivalent in number to the presence points that were collected during the field work. We then re-run the algorithm 10 times as recommended by Barbet-Massin et al. (2012), as tree-based machine learning algorithms requires this amount of runs at least when the number of presence points is less than 1,000 (Barbet-Massin et al., 2012).

Twenty-one replicates of MaxEnt models were fit with different regularization multiplier values $(0-10$ with an interval of 0.5 ) to regulate model complexity, using the DISMO package (Hijmans et al., 2013). We used the MIAmaxent $\mathrm{R}$ package for variable transformation and model selection for species distribution models. We finally retained the model with regularization multiplier of 3.5 due to the best cross-validation performance. We used the caret package in $\mathrm{R}$ to tune the parameters in the GAM models for choosing the optimal model across our parameters. Accuracy was used to select the optimal model using the largest value as criteria.

For the GBM approach, we built several models by setting the back fraction to the default value (0.75; Elith et al., 2008) and by using different combinations of tree complexity levels $(1-5)$ and learning rates (slightly varying values ranging from 0.0001 to 0.05$)$ from the "gbm.step" function in the gbm package (Ridgeway, 2013). From models with more than 1,000 trees, the least number of trees by default; see Elith et al. (2008), we selected the combination of tree complexity levels and learning rates that provided the lowest cross-validation deviance.

For each of the performed algorithms, we ran a fivefold cross-validation procedure and repeated it 10 times. To this end, we divided our data into five equal subsets, ran the cross-validation procedure, and repeated these steps 10 times. For each of the mentioned algorithms, we then calculated predictions from the weighted mean across all repeats and folds. All the three final models were validated against the test data set by means of the AUC and TSS accuracy metrics (Swets, 1988). The reported AUC of each algorithm is the average AUC computed across the repeated fivefold cross-validation. We also report TSS (true skill statistics) as an average across the repeated fivefold crossvalidation. TSS was calculated as "sensitivity" + "specificity" - 1 (Allouche et al., 2006).

\section{Spatial and Temporal Projections of Models}

All models from the three algorithms were projected to all Ethiopian highlands (areas > 2,300 m; Figure 1), both for current and projected future climates representing the year 2080 using data from the Community Climate System Model version 4 (CCSM4) by relying on all the four emission scenarios (RPCs 2.6, $4.5,6.0$, and $8.5 \mathrm{Wm}^{2}$ of radiative forcing).

The probabilistic prediction maps obtained from models runs as well as projections were split into binary presenceabsence maps using three threshold criteria: (1) Minimum presence threshold, selecting the minimum probability value among occurrence points; (2) Maximum sum threshold (Maximum Sensitivity plus Specificity), maximizing the sum of sensitivity and specificity (Liu et al., 2005); and (3) Maximum Kappa, using the threshold that provides highest Cohen's Kappa values. All nine binary ensemble maps (three algorithms $\times$ three probability threshold criteria) were combined to define three habitat suitability classes: Unsuitable habitat, where less than 30\% (maximum two out of nine) binary maps predict presence; Uncertain suitability, where $30-60 \%$ (3-5) maps predict presence; and Suitable habitat, where $>60 \%$ (more than five) maps predict presence following Chala et al. (2016).

Future habitat suitability ensembles were produced by combining 36 maps (three algorithms, three threshold criteria and four emission scenarios) and produced the three habitat suitability classes following the same approach that was applied to the ensemble current habitat suitability map. We performed a MESS analyses (Elith et al., 2010) by using the R-package "dismo" (Hijmans et al., 2013). The MESS analyses show how far pixel values in the predictors are outside the range of presences in the training data. Negative values indicate that one or more predictors are outside this range and the MESS values decreases in accordance with the dissimilarity. Thus pixels with negative MESS values were ruled out and not included in the results.

\section{Correction for Lack of Species Occurrences in Steep Areas}

Ibex species are specialized to steep cliffs up to $60^{\circ}$ (Nievergelt, 1981), which are difficult to access for predators and other organisms (Shackelton, 1997). The steepest areas $\left(>45^{\circ}\right)$ are, however, not likely to be well covered by species occurrence data obtained through visual observation, as in our case. Thus, we assumed that our presence-based models mainly captured the climate requirement of Walia, without fully capturing the topographic requirements, due to under-sampling of the steepest slopes. In order to take into account this source of bias, we repeated the whole analyses such that occurrences of Walia ibex in gentle slopes far away from steep cliffs were removed from the presence data set. We also repeated the whole analyses and built models without slope as predictor. We compared the two model versions, and filtered flat areas from both. To filter flat areas far away from steep cliffs, we calculated the average slope among occurrence points. Then we flagged all occurrence 
points for which the slope was lower than the mean value and calculated the distance between these points and the nearest cliff with slope above the mean. We computed the first (lower) quartile, the third (upper) quartile, and the interquartile range (IQR). In this way, we restricted the presence points for the Walia ibex to include only suitable habitats that overlap with the cliffs that are above mean values of the slope angle and any suitable habitat within the distance of the sum of the upper quartile value plus 1.5 times the IQR from these cliffs. Overall, for both current and future climate conditions we present two versions of habitat suitability maps for the Simen Mountains and other Ethiopian mountains, i.e., maps with and without steep area correction.

\section{Landscape Connectivity}

We performed a landscape connectivity analyses in order to provide an estimation of the habitat that can be spontaneously colonized by the Walia ibex under present and projected future climate conditions. Thus, we calculated two different connectivity indices in the program package FRAGSTATS (McGarigal, 2002): the proximity index and the connectance index. This analysis was limited to suitable habitats inside a "landscape" of $100 \times 100 \mathrm{~km}$ with the current occurrence points of Walia ibex in the center, because available data on species distribution and movements do not support the idea of spontaneous dispersal over broader scales. Other typologies of connectivity analyses were hampered by limited data on species movements and lack of high-resolution information on fine-scale landscape elements that could act as barriers.

In this analysis, suitable habitats are defined as the habitats currently used by the Walia ibex. The proximity index is calculated between a given habitat spot (patch) and all other habitat spots of the same type. The sum of the area of the habitat spots $\left(\mathrm{m}^{2}\right)$ is divided by the square of nearest edge-to-edge distance $\left(\mathrm{m}^{2}\right)$. Therefore, the proximity index has higher values at increasing amounts of suitable areas and if suitable areas are nearby. The connectance index is the number of connections (c) between all habitat spots of the same type (i) (sum of cijk, where cijk $=0$ if spot $\mathrm{j}$ and $\mathrm{k}$ are not within the specified distance from each other, and cijk $=1$ if spot $\mathrm{j}$ and $\mathrm{k}$ are within the landscape, divided by the total number of possible connections between all spots of the same type, multiplied by 100 to give a percentage value (values between 0 and 100).

\section{RESULTS}

\section{Predictions Under Current Climate}

The three statistical models showed similarly high performance, with average AUC and TSS values from all model runs per algorithm: $\mathrm{AUC}=0.902$ and $\mathrm{TSS}=0.846$ for GAM, AUC $=0.905$ and $\mathrm{TSS}=0.853$ for $\mathrm{GBM}$, and $\mathrm{AUC}=0.906$ and TSS $=0.855$ for MaxEnt. The predicted suitability patterns were also similar for the models (Supplementary Figures 1, 2). Our results consistently showed that suitable habitat for the Walia ibex is available in the Simen Mountains, also in areas where the species is not currently known to exist. The model projections suggested that there is $501-672 \mathrm{~km}^{2}$ of suitable habitat in the Simen Mountains (Figure 2 and Table 1), considerably larger than the currently delineated protected area (Figure 1).

Projecting the models to all Ethiopian highland areas suggested that suitable habitat is not only present in the Simen mountains, but also in the several other mountain fragments in northwestern Ethiopia (Supplementary Figure 2). The GAM model also predicted suitable habitats in the southern highlands of Ethiopia, in the Bale and Arsi Mountains, southeast of the Rift Valley (Supplementary Figure 2). In the other two models, this was only the case when the minimum presence threshold was used. The models without slope as predictor resulted in reduced suitable habitat area, namely a $21.4 \%$ reduction in the Simen Mountains and a $20.4 \%$ reduction across all Ethiopian highlands (Table 1). The impact of under-sampling of the steepest slopes was lower in the Simen Mountains $(-13.6 \%)$ than in other Ethiopian mountains (-28.4\%; Table 1).

Overall, the modeling approaches indicate that there are fragmented patches with potentially high habitat suitability, mostly in the central northern highlands, west of the Rift Valley, and that most of these patches are isolated (Figure 3 and Supplementary Figure 2).

\section{Predictions Under Projected Climate Change}

Model projections under future emission scenarios indicated a tendency of shifting suitable habitats toward higher altitudes, both in the Simen and in the other Ethiopian mountains (Supplementary Figure 1). Upward range shifts resulted in an expansion ranging from $501-672$ to $1,164-1,243 \mathrm{~km}^{2}$ of suitable habitat in Simen, depending on model and scenario applied. The opposite pattern was detected in other Ethiopian mountains (a reduction ranging from $6,251-7,732$ to $4,922-5,812 \mathrm{~km}^{2}$ ), with consistent results across models. Correction for under-sampling of the steepest slopes had less pronounced impact under climate change scenarios, especially in mountain areas outside Simen, reflecting that less flat area is found to be available or suitable toward mountain summits (Table 1). The MESS analyses showed four mountain areas outside Simen where our predictions may be unreliable (Figure 4). One of these areas was in the northern part of Ethiopia close to Dessie and three other areas in the South. The prediction cells in these territories were ruled out and excluded from the reported results.

\section{Habitat Connectivity}

The proximity analysis identified that several suitable areas are well connected to currently occupied patches (Figure 5). Under scenarios of climate change, some increase of connectivity levels are expected, with an increase up to $5.86 \%$, particularly in the central Simen area. This is likely caused by the prediction of more future suitable habitats in this area. Slight increases of the proximity index under climate change may suggest that larger suitable patches in areas with high elevation would become better 

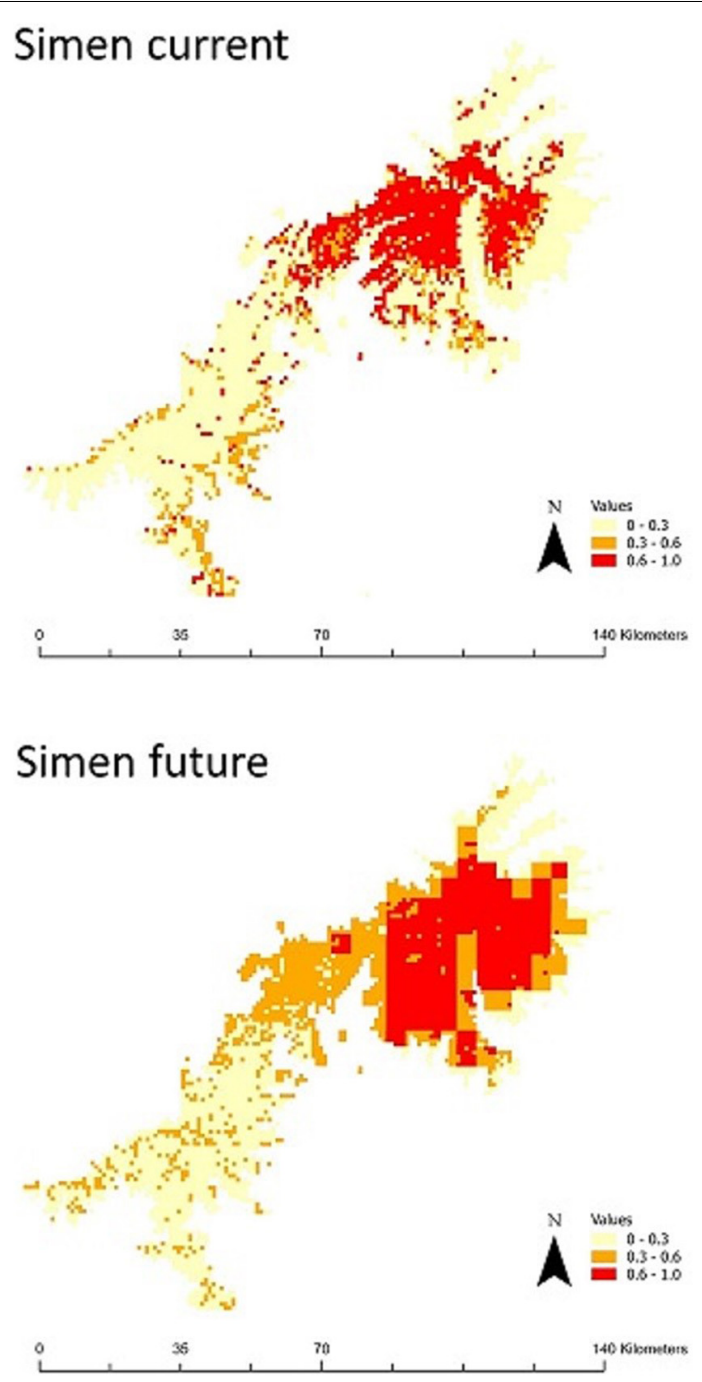

\section{Simen current corrected for slope}

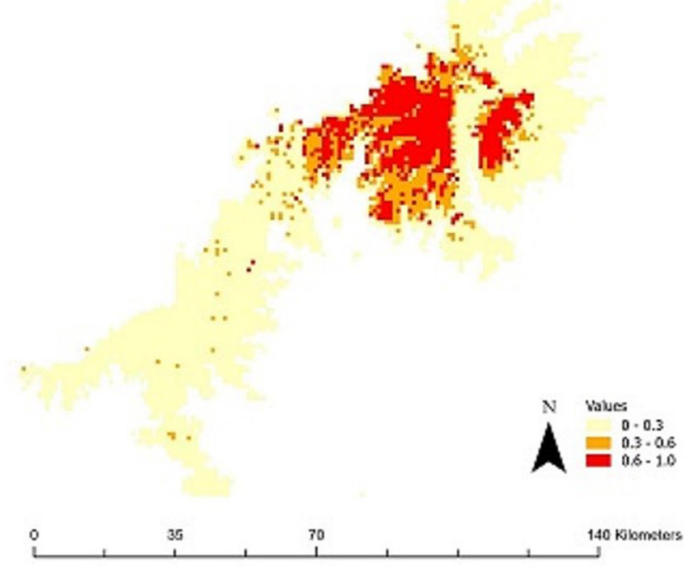

Simen future corrected for slope

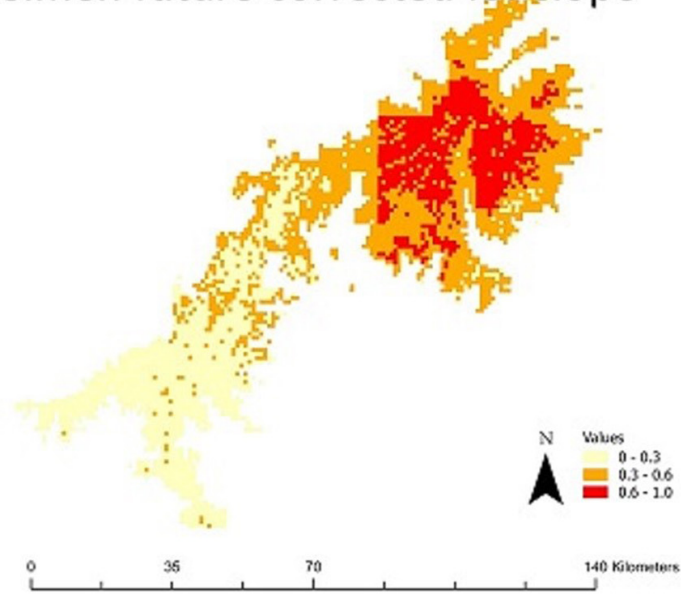

FIGURE 2 | Comparison of habitat suitability under current and future climate in the Simen Mountains. Current suitability maps are produced by averaging nine maps ( 3 algorithms $\times 3$ threshold values). Future habitat suitability is produced by averaging 36 ( 3 algorithms $\times 3$ threshold values $\times 1$ climate model $\times 4$ emission scenarios). The numbers on the legend bar refer to the degree of agreement among these maps in predicting presence: 0-0.3 unsuitable with high certainty, $0.3-0.6$ uncertain suitability, $>0.6$ suitable with high certainty. Slope is excluded as a predictor variable and correction is made for under-sampling of steep slopes in the maps on the right panels.

TABLE 1 | The total area $\left(\mathrm{km}^{2}\right)$ of suitable habitat predicted with high certainty (>60\% agreement for presence among models) in the Simen Mountains and among all Ethiopian highland masses (above 2,300 m), and correction for under-sampling of the steepest slopes.

\begin{tabular}{|c|c|c|c|c|c|c|c|c|}
\hline & \multicolumn{4}{|c|}{ Simen mountains } & \multicolumn{4}{|c|}{ Whole Ethiopia } \\
\hline & \multicolumn{2}{|c|}{ With slope } & \multicolumn{2}{|c|}{ Without slope } & \multicolumn{2}{|c|}{ With slope } & \multicolumn{2}{|c|}{ Without slope } \\
\hline Suitable habitat & 738 & 1,418 & 580 & 1,345 & 10,970 & 6,626 & 8,731 & 7,100 \\
\hline Suitable habitat* & 672 & 1,243 & 501 & 1,164 & 7,732 & 4,922 & 6,251 & 5,812 \\
\hline
\end{tabular}

${ }^{*}$ Area of suitable habitat corrected for under sampling of the steepest slopes.

connected in the future. In the opposite direction, connectance tended to decrease (Table 2), suggesting increasing distances between the total of patches, where the ibex at lower elevation would have to traverse larger areas of less suitable habitat.

\section{DISCUSSION}

This study is the first to examine both the current and future potential suitable habitats of the charismatic Walia ibex for 
all Ethiopian highlands, assessing in particular the expected impacts of climate change on habitat suitability. Our findings have important bearings on conservation management under changing climate and land use in Ethiopia. Indeed, our results demonstrate that there is suitable habitat available in the Simen Mountains and also in other Ethiopian mountains that is not yet realized, both under current and projected future climates. The particularly high suitability within the Simen Mountains confirms the significance of the area as a refuge for this endangered mountain mammal. All projected areas of high habitat suitability are located west of the Ethiopian Rift Valley, while suitability is generally lower on the eastern side (Figure 3). The projected area of suitable habitat varies depending on the predictors used in the model calibration, as models without slope tended to predict smaller areas of suitable habitat (Table 1).

Notably, our projections under climate change scenarios for the year 2080 suggest the possibility of an increase in the area of suitable habitat within the Simen Mountains, the only area where the species occurs today. In contrast, we found the opposite trend for all other parts of the Ethiopian highlands (Table 1). The projected expansion in the Simen Mountains is contrary to the general expectation of a shrinking of suitable areas for high-elevation species in response to climate warming and may be attributed to the ruggedness of the mountains, as has also been suggested in other areas of the world (Elsen and Tingley, 2015). The wide altitudinal range of the Walia ibex, and its ability to exploit the steepest slopes, might allow the species to track the expected vegetation shift to higher altitudes. The Simen is a complex mountain range with rugged topography presenting steep slopes compared to other Ethiopian mountains. As a consequence, the ibex could find additional, currently unexploited habitats under climate change (see Supplementary Figure 1). However, the potentially positive impact in Simen may not last very long under continued climate warming after

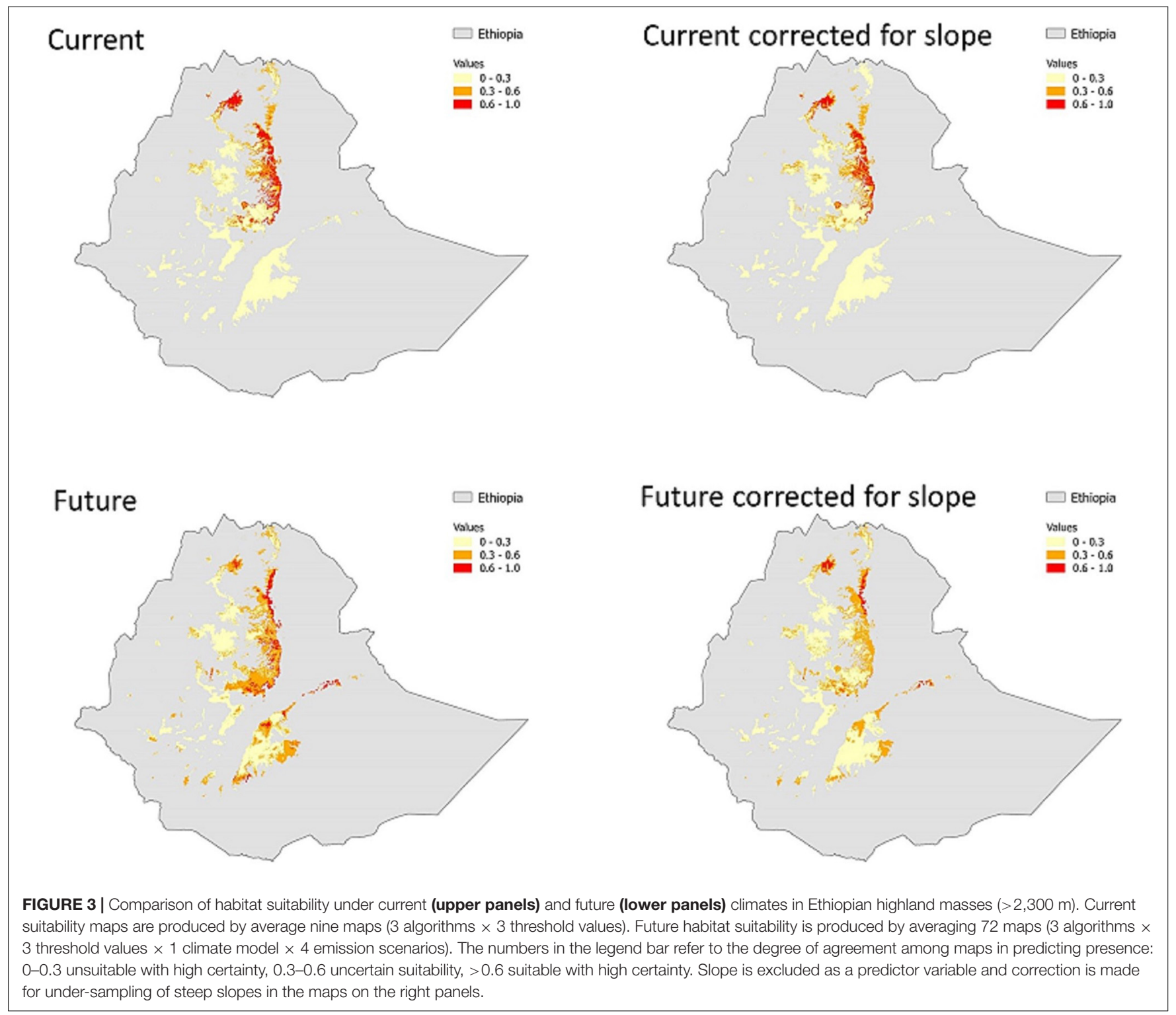




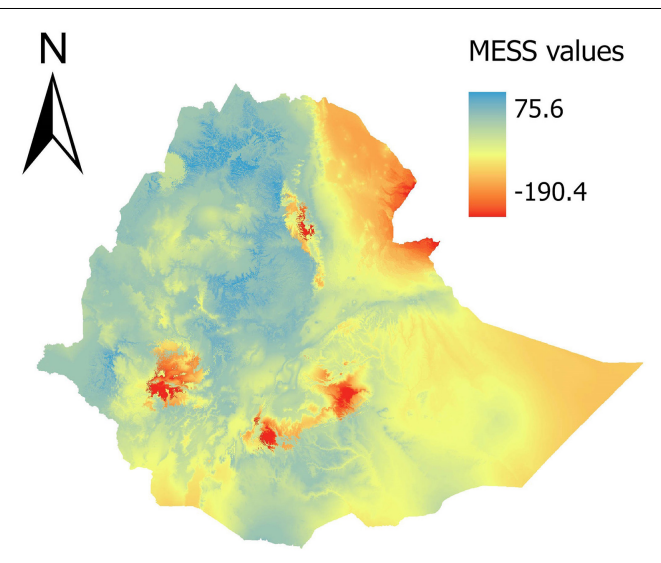

FIGURE 4 | MESS analysis. Negative MESS values showed by red colors have one or more predictors outside the range of present in the training data. Deeper red colors show larger differences and predictions here should be treated with strong caution.

2080, as the species will not have much more new space left to colonize.

A study on the impact of climate change on the gelada baboon (Theropithecus gelada) suggests that baboons could shift their lower altitudinal limit $(>2,000 \mathrm{~m})$ upward by about $500 \mathrm{~m}$ for every $2^{\circ} \mathrm{C}$ of increase in mean annual temperature, resulting in a loss of up to $32 \%$ in range size (Dunbar, 1998). Such a shift is primarily driven by the dietary behavior of this primate, which mainly feeds on grasses (Dunbar and Bose, 1991). The niche of the gelada baboon partially overlaps with the Walia ibex (Nievergelt, 1981) and it is documented that the Walia ibex previously could have inhabited lower altitudes, as low as 2,300 $\mathrm{m}$ a.s.l. (Nievergelt, 1981). In our surveys, however, tracks of the species were never observed below 2,700 m, which could imply that a shift toward higher elevations has already started. It is difficult to determine whether such a shift was caused by climate change or by direct anthropogenic impact. However, in the last few decades, agricultural expansion at low altitudes has been intensive, suggesting that habitat loss and/or competition with domestic goats (Gebremedhin et al., 2016) could have forced the ibex to move upwards. In our study, we did not include projections of land-use change, given the lack of high-resolution projections for the study area. However, regional analyses suggest that agricultural increase could cause further habitat shrinkage in the future (Williams et al., 2021), thus the prevention of habitat loss from agriculture is a conservation priority for the next years.

IUCN's guidelines for planning and managing protected areas recommend that protected areas (PAs) should be large and continuous with limited edge effects and with high connectivity to other areas of suitable habitat (Hamilton and McMillan, 2004). The Simen Mountains National Park satisfies none of these criteria, as it has been affected by considerable human intervention (Hurni et al., 2010). In addition to direct

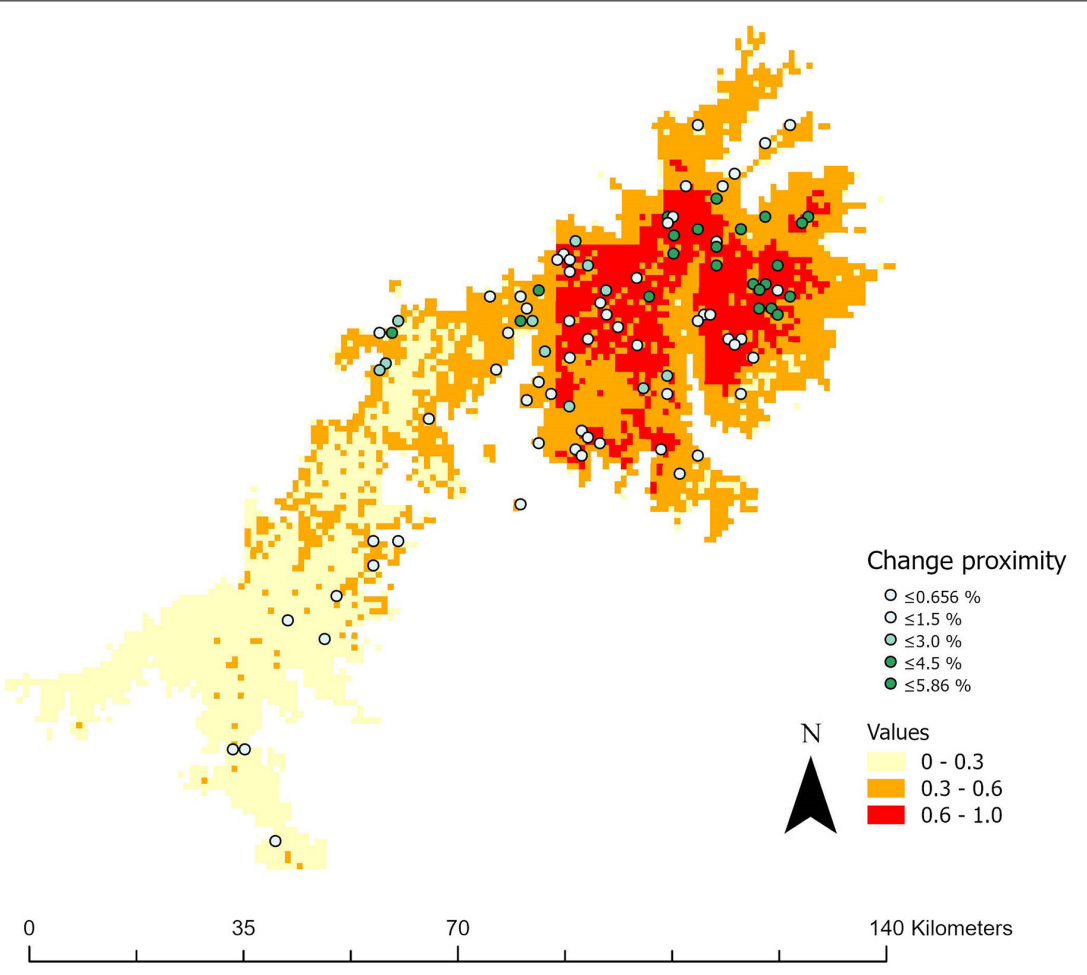

FIGURE 5 | Landscape proximity between present and suitable habitats for Walia ibex. The raster colors indicate the present-day proximity values. The dots represent the centroid of each suitable habitat patch. The color of the dots show how much the proximity value in each suitable patch would change (in percent) in the Simen mountain according to the prediction model Simen future corrected for slope showed in Figure 2 lower right. 
TABLE 2 | Average values for Proximity index and Connectance index for suitable habitat patches in the Simen Mountains, respectively, under current climate and future projection.

\begin{tabular}{lcc}
\hline & Proximity & Connectance \\
\hline Simen current & 22.0695 & 7.8886 \\
Simen future projection & 23.2189 & 7.2981 \\
\hline
\end{tabular}

anthropogenic factors, we show that climate warming will force the species to move further upwards. Under these circumstances, the pressure on small-sized protected areas such as the Simen Mountains National Park will become extremely high. Given the recent increase in population size of the Walia ibex, animals may already soon have to expand beyond the protected areas (Mason et al., 2014). The combination of anthropogenic factors, competition with livestock, and climate change may lead to further changes in the species' range dynamics that may render the small-sized currently protected area of insufficient quality in future conservation strategies and prompt the need for expansion of such areas. Indeed, future consideration of areas for reintroduction or translocation should focus on those that are well connected with other afro-alpine, sub-afro-alpine and montane ecosystems.

In response to the increasing human pressure on the habitats of the Walia ibex and the overall afro-alpine biodiversity, the total area of the Simen Mountains National Park was recently expanded from $\sim 225$ to $412 \mathrm{~km}^{2}$. With the enlargement of the protected area, the boundaries were redesigned to connect the currently occupied areas to the historical species distribution. So far, no animal movement to the reconnected areas has been observed. Our connectivity analysis suggests that proximity values between the Simen and some nearby suitable areas are not low, thus the expansion to nearby areas is in principle possible (Figure 5). However, our connectivity analyses focused on broad-scale suitability values, and did not take into account fine-scale landscape elements, such as barriers, that could actually hamper the movements of ibexes. More accurate assessments of potential colonization pathways would require high-resolution data on the occurrence of barriers, and better information on the actual movements of ibexes, for example through radiotracking. Such data would allow to identify areas where additional corridors and protected areas could be defined in order to increasing the chance for spontaneous re-colonization of historical sites.

Our study has identified potential key sites that can support re-established populations of the Walia ibex outside its current distribution range and has pointed to areas in which the species will also find suitable habitats under projected future climates. Planning and implementing conservation actions like reintroducing and translocating animals to other mountain areas have been successful for several close relatives of the Walia ibex, such as e.g., the Alpine ibex, C. ibex (Maudet et al., 2002). The Alpine ibex, endemic to the Alps in Europe, was driven very close to extinction in the early nineteenth century, when less than 100 individuals were estimated to be left in a single protected area in Italy (Stüwe and Nievergelt, 1991). The reintroduction to multiple sites within the historical range of the Alpine ibex in 1911 allowed populations to grow and to colonize many areas across all of the Alps (Hirzel et al., 2002). Such efforts are needed in order to conserve the Walia ibex in the highlands of the Ethiopian mountains.

Reintroductions are complex management actions that can have impacts also on the species that currently are resident in the target areas. Hence, it is important to consider the possible interactions between translocated species and the resident ones. Interspecific competition is one of the major potential issues. In a study conducted to assess the spatial overlap between reintroduced Bison (Bison bison) and resident ungulates, Jung et al. (2015) conclude that the overall potential for competition between reintroduced bison and resident ungulates is low, still they highlight that competition could occur across multiple niche dimension axes. A study on seven species of herbivores in the Simen Mountains suggested limited levels of competition (Dunbar, 1978). This could be because several of the species were in the process of re-establishing themselves following periods of absence or reduced density, so that competition was more likely to be incipient rather than actual.

The potential wild competitors for the Walia ibex in the Simen Mountains include the gelada baboon and the klipspringer (Oreotragus oreotragus) (Nievergelt, 1981). However, the density of klipspringer in the park is very low and the competition that may arise should not significantly affect the Walia ibex population (Dunbar, 1978). On the other hand, the density of domestic livestock in the study area has increased to a higher level over the last four decades (Gebremedhin et al., 2016). Studies performed on related species in India (Bagchi et al., 2004) observed very strong interactions between the Himalayan ibex (C. sibirica) and livestock species, suggesting that domestic livestock deplete the density and diversity of wild herbivores in the cold deserts of the Trans-Himalaya by imposing resource limitations. Similarly, using metabarcoding methodology Gebremedhin et al. (2016) documented potential competition with domestic goats in the Simen mountains. Even though reintroductions have a great potential to allow the Walia ibex regaining its historical range, accurate analyses of competition with both native and domestic species will be pivotal for the success of conservation actions.

\section{CONCLUSION}

The population size of the Walia ibex recently increased from 150 individuals in the early 1990s to a minimum of 957 individuals at present. Although the population increase is good news for the conservation of this iconic species, new tasks are ahead. The area currently protected by the National Park is very small, potentially leading to fierce competition for resources within the population as well as with the increasing number of domestic animals (Gebremedhin et al., 2016). Given the projected habitat suitability under climate change, new areas need to be considered for expanding the distribution of the Walia ibex. If appropriate management actions are undertaken, such as well-planned 
translocations and the building of suitable migration corridors (Stüwe and Nievergelt, 1991; Clark et al., 2002; Hirzel et al., 2002), the species could expand its population further, especially in the Simen Mountains, but potentially also in other areas west of the Ethiopian Rift Valley. A future presence of the Walia ibex in several interconnected mountain fragments that ideally form a functional metapopulation would certainly increase the viability and future prospects of this charismatic flagship species. The historically successful strategy of reintroduction of the once-nearly extinct species of the Alpine ibex that has roamed to the whole Alps mountains should be taken as a lesson to enable the Walia ibex to occupy suitable habitat in the Simen and other mountains west of the Rift Valley.

\section{DATA AVAILABILITY STATEMENT}

The original contributions presented in the study are included in the article/Supplementary Material, further inquiries can be directed to the corresponding author/s.

\section{ETHICS STATEMENT}

Ethical review and approval was not required for the animal study because the study didn't require animal handling. The field survey and data collection were conducted without disturbing the animals.

\section{REFERENCES}

Allouche, O., Tsoar, A., and Kadmon, R. (2006). Assessing the accuracy of species distribution models: prevalence, kappa and the True Skill Statistic (TSS). J. Appl. Ecol. 43, 1223-1232. doi: 10.1111/j.1365-2664.2006.01214.x

Araújo, M. B., Cabeza, M., Thuiller, W., Hannah, L., and Williams, P. H. (2004). Would climate change drive species out of reserves? An assessment of existing reserve-selection methods. Glob. Change Biol. 10, 1618-1626. doi: 10.1111/j. 1365-2486.2004.00828.x

Araújo, M. B., and New, M. (2007). Ensemble forecasting of species distributions. Trends Ecol. Evol. 22, 42-47. doi: 10.1016/j.tree.2006.09.010

Arino, O., Perez, J. J. R., Kalogirou, V., Bontemps, S., Defourny, P., and Van Bogaert, E. (2012). Global land cover map for 2009 (GlobCover 2009). PANGAEA - Data Publisher for Earth \& Environmental Science.

Bagchi, S., Mishra, C., and Bhatnagar, Y. V. (2004). Conflicts between traditional pastoralism and conservation of Himalayan ibex (Capra sibirica) in the Trans-Himalayan mountains. Anim. Conserv. 7, 121-128. doi: 10.1017/ s1367943003001148

Barbet-Massin, M., Jiguet, F., Albert, C. H., and Thuiller, W. (2012). Selecting pseudo-absences for species distribution models: how, where and how many? Methods Ecol. Evol. 3, 327-338. doi: 10.1111/j.2041-210x.2011.00172.x

Barnosky, A. D., Matzke, N., Tomiya, S., Wogan, G. O., Swartz, B., Quental, T. B., et al. (2011). Has the Earth's sixth mass extinction already arrived? Nature 471, 51-57. doi: 10.1038/nature09678

Bellard, C., Bertelsmeier, C., Leadley, P., Thuiller, W., and Courchamp, F. (2012). Impacts of climate change on the future of biodiversity. Ecol. Lett. 15, 365-377. doi: 10.1111/j.1461-0248.2011.01736.x

Chala, D., Brochmann, C., Psomas, A., Ehrich, D., Gizaw, A., Masao, C., et al. (2016). Good-bye to tropical alpine plant giants under warmer climates? Loss of

\section{AUTHOR CONTRIBUTIONS}

BG collected the data in the field. DC conducted the data analyses with input from VB, NZ, and GF. BG and $\varnothing \mathrm{F}$ drafted the manuscript and was improved and revised by all coauthors. All authors contributed to the intellectual conception and design of the study.

\section{FUNDING}

This work was funded by CEES and NHM at the University of Oslo and the Rufford Small Grants for Nature Conservation (RSG 8960-1).

\section{ACKNOWLEDGMENTS}

We thank Ethiopian Wildlife Conservation Authority (EWCA) and Simen Mountains National Park (SMNP) for the permission to carry out the fieldwork. We thank to the two reviewers for their constructive comments and suggestions.

\section{SUPPLEMENTARY MATERIAL}

The Supplementary Material for this article can be found online at: https://www.frontiersin.org/articles/10.3389/fevo.2021. 611632/full\#supplementary-material

range and genetic diversity in Lobelia rhynchopetalum. Ecol. Evol. 6, 8931-8941. doi: $10.1002 /$ ece3.2603

Clark, J. D., Huber, D., and Servheen, C. (2002). Bear reintroductions: lessons and challenges: invited paper. Ursus $13,335-345$.

Dunbar, R. (1998). Impact of global warming on the distribution and survival of the gelada baboon: a modelling approach. Glob. Change Biol. 4, 293-304. doi: 10.1046/j.1365-2486.1998.00156.x

Dunbar, R., and Bose, U. (1991). Adaptation to grass-eating in gelada baboons. Primates 32, 1-7. doi: 10.1007/BF02381596

Dunbar, R. I. M. (1978). Competition and niche separation in a high altitude herbivore community in Ethiopia. Afr. J. Ecol. 16, 183-199. doi: 10.1111/j.13652028.1978.tb00439.x

Early, R., and Sax, D. F. (2011). Analysis of climate paths reveals potential limitations on species range shifts. Ecol. Lett. 14, 1125-1133. doi: 10.1111/j. 1461-0248.2011.01681.x

Ejigu, D., Bekele, A., and Powell, L. (2017). Walia ibex have increased in number and shifted their habitat range within Simien Mountains National Park, Ethiopia. J. Mount. Ecol. 10, 27-44.

Ejigu, D., Bekele, A., Powell, L., and Lernould, J. M. (2015). Habitat preference of the endangered Ethiopian walia ibex (Capra walie) in the simien mountains national park, Ethiopia. Anim. Biodivers. Conserv. 38, 1-10. doi: 10.32800/abc. 2015.38.0001

Elith, J., Kearney, M., and Phillips, S. (2010). The art of modelling range-shifting species. Methods Ecol. Evol. 1, 330-342. doi: 10.1111/j.2041-210x.2010.00036.x

Elith, J., Leathwick, J. R., and Hastie, T. (2008). A working guide to boosted regression trees. J. Anim. Ecol. 77, 802-813. doi: 10.1111/j.1365-2656.2008. 01390.x

Elsen, P. R., and Tingley, M. W. (2015). Global mountain topography and the fate of montane species under climate change. Nat. Clim. Chang. 5, 772-776. doi: $10.1038 /$ nclimate2656 
Friedman, J., Hastie, T., and Tibshirani, R. (2000). Additive logistic regression: a statistical view of boosting (with discussion and a rejoinder by the authors). Ann. Stat. 28, 337-407.

Galvin, M., and Haller, T. (2008). People, protected areas and global change: participatory conservation in Latin America, Africa, Asia and Europe. Bern, Switzerland: NCCR North-South.

Gebremedhin, B., Ficetola, G., Naderi, S., Rezaei, H. R., Maudet, C., Rioux, D., et al. (2009). Combining genetic and ecological data to assess the conservation status of the endangered Ethiopian Walia ibex. Anim. Conserv. 12, 89-100. doi: $10.1111 /$ j.1469-1795.2009.00238.x

Gebremedhin, B., Ficetola, G. F., Flagstad, $\varnothing$, and Taberlet, P. (2010). Demography, distribution and management of Walia ibex (Capra walie). Galemys 22, 421-432.

Gebremedhin, B., Flagstad, Ø, Bekele, A., Chala, D., Bakkestuen, V., Boessenkool, S., et al. (2016). DNA metabarcoding reveals diet overlap between the endangered Walia ibex and domestic goats-implications for conservation. PLoS One 11:e0159133. doi: 10.1371/journal.pone.0159133

Gordon, I. J. (2009). What is the future for wild, large herbivores in humanmodified agricultural landscapes? Wildl. Biol. 15, 1-9. doi: 10.2981/06-087

Guisan, A., and Zimmermann, N. E. (2000). Predictive habitat distribution models in ecology. Ecol. Modell. 135, 147-186. doi: 10.1016/S0304-3800(00)00354-9

Halvorsen, R. (2013). A strict maximum likelihood explanation of MaxEnt, and some implications for distribution modelling. Sommerfeltia 36, 1-132. doi: 10.2478/v10208-011-0016-2

Halvorsen, R., Mazzoni, S., Bryn, A., and Bakkestuen, V. (2015). Opportunities for improved distribution modelling practice via a strict maximum likelihood interpretation of MaxEnt. Ecography 38, 172-183. doi: 10.1111/ecog.00565

Hamilton, L. S., and McMillan, L. (2004). Guidelines for planning and managing mountain protected areas. Gland, Switzeland: IUCN.

Hijmans, R., Phillips, S., Leathwick, J., and Edith, J. (2013). Dismo. Species distribution modelling. $R$ package version 0.9-3. Available online at: http:// CRAN.R-project.org/packages=desmo

Hijmans, R. J., Cameron, S. E., Parra, J. L., Jones, P. G., and Jarvis, A. (2005). Very high resolution interpolated climate surfaces for global land areas. Int. J. Climatol. 25, 1965-1978. doi: 10.1002/joc.1276

Hirzel, A. H., Hausser, J., Chessel, D., and Perrin, N. (2002). Ecological-niche factor analysis: how to compute habitatsuitability maps without absence data? Ecology 83, 2027-2036. doi: 10.1890/0012-9658(2002)083[2027:enfaht]2.0.co;2

Hurni, H., Abate, S., Bantider, A., Debele, B., Ludi, E., Portner, B., et al. (2010). "Land degradation and sustainable land management in the highlands of Ethiopia," in Global Change and Sustainable Development: A Synthesis of Regional Experiences From Research Partnerships, eds H. Hurni and U. Wiesmann (Bern: University of Bern), 187-201.

IUCN. (2013). Guidelines for reintroductions and other conservation translocations. Gland, Switzerland: IUCN.

Jarvis, A., Reuter, H. I., Nelson, A., and Guevara, E. (2008). Hole-filled SRTM for the globe Version 4. Available online at: http://srtm.csi.cgiar.org)

Jung, T. S., Hegel, T. M., Stotyn, S. A., and Czetwertynski, S. M. (2015). Cooccurrence of reintroduced and resident ungulates on a shared winter range in northwestern Canada. Écoscience 22, 7-16. doi: 10.1080/11956860.2015. 1047133

Leadley, P. (2010). Biodiversity scenarios: projections of $21^{\text {st }}$ century change in biodiversity, and associated ecosystem services: a technical report for the global biodiversity outlook 3. Nairobi, Kenya: UNEP/Earthprint.

Lenoir, J., Gégout, J. C., Marquet, P., De Ruffray, P., and Brisse, H. (2008). A significant upward shift in plant species optimum elevation during the 20th century. Science 320, 1768-1771. doi: 10.1126/science.1156831

Liu, C., Berry, P. M., Dawson, T. P., and Pearson, R. G. (2005). Selecting thresholds of occurrence in the prediction of species distributions. Ecography 28, 385-393. doi: 10.1111/j.0906-7590.2005.03957.x

Lobo, J. M., Jimenez-Valverde, A., and Hortal, J. (2010). The uncertain nature of absences and their importance in species distribution modelling. Ecography 33, 103-114. doi: 10.1111/j.1600-0587.2009.06039.x

Lovari, S., Franceschi, S., Chiatante, G., Fattorini, L., Fattorini, N., and Ferretti, F. (2020). Climatic changes and the fate of mountain herbivores. Clim. Change 162, 2319-2337. doi: 10.1007/s10584-020-02801-7
Marmion, M., Parviainen, M., Luoto, M., Heikkinen, R. K., and Thuiller, W. (2009). Evaluation of consensus methods in predictive species distribution modelling. Divers. Distrib. 15, 59-69. doi: 10.1111/j.1472-4642.2008.00491.x

Mason, T. H., Stephens, P. A., Apollonio, M., and Willis, S. G. (2014). Predicting potential responses to future climate in an alpine ungulate: interspecific interactions exceed climate effects. Glob. Change Biol. 20, 3872-3882. doi: 10. $1111 /$ gcb. 12641

Maudet, C., Miller, C., Bassano, B., Breitenmoser-Würsten, C., Gauthier, D., Obexer-Ruff, G., et al. (2002). Microsatellite DNA and recent statistical methods in wildlife conservation management: applications in Alpine ibex [Capra ibex (ibex)]. Mol. Ecol. 11, 421-436. doi: 10.1046/j.0962-1083.2001.01451.x

McGarigal, K. (2002). FRAGSTATS: Spatial Pattern Analysis Program for Categorical Maps. Computer software program produced by the authors at the University of Massachusetts, Amherst. Available online at: http://www.umass. edu/landeco/research/fragstats/fragstats.html

McNeely, J. A. (1994). Protected areas for the $21^{\text {st }}$ century: working to provide benefits to society. Biodivers. Conserv. 3, 390-405. doi: 10.1007/BF00057797

Meller, L., Cabeza, M., Pironon, S., Barbet-Massin, M., Maiorano, L., Georges, D., et al. (2014). Ensemble distribution models in conservation prioritization: from consensus predictions to consensus reserve networks. Divers. Distrib. 20, 309-321. doi: 10.1111/ddi.12162

Morrison, J. C., Sechrest, W., Dinerstein, E., Wilcove, D. S., and Lamoreux, J. F. (2007). Persistence of large mammal faunas as indicators of global human impacts. J. Mammal. 88, 1363-1380. doi: 10.1644/06-MAMM-A-124R2.1

Nievergelt, B. (1981). Ibexes in an African Environment: Ecology and Social Systems of the Walia Ibex in the Simen Mountains, Ethiopia. Berlin: Springer Verlag.

Phillips, S. J., Anderson, R. P., and Schapire, R. E. (2006). Maximum entropy modelling of species geographic distributions. Ecol. Modell. 190, 231-259. doi: 10.1016/j.ecolmodel.2005.03.026

Pimm, S. L., Russell, G. J., Gittleman, J. L., and Brooks, T. M. (1995). The future of biodiversity. Science 269:347. doi: 10.1126/science.269.5222.347

Pounds, J. A., Fogden, M. P., and Campbell, J. H. (1999). Biological response to climate change on a tropical mountain. Nature 398, 611-615. doi: 10.1038/ 19297

Puff, C., and Nemomissa, S. (2005). Plants of the simen: a flora of the Simen Mountains and surroundings, northern Ethiopia. Scripta Botanica Belgica 37:258.

Ridgeway, G. (2013). gbm: Generalized boosted regression models. $R$ package version 2.1. Available online at: http://CRAN.R-project.org/packages=gbm

Seddon, P. J., Armstrong, D. P., and Maloney, R. F. (2007). Developing the science of reintroduction biology. Conserv. Biol. 21, 303-312. doi: 10.1111/j.1523-1739. 2006.00627.x

Shackelton, D. (1997). Wild sheep and goats and their relatives. Status survey and conservation action plan for Caprinae. IUCN/SSC Caprinae Specialists Group. Gland, Switzerland: IUCN.

Stüwe, M., and Nievergelt, B. (1991). Recovery of alpine ibex from near extinction: the result of effective protection, captive breeding, and reintroductions. Appl. Anim. Behav. Sci. 29, 379-387. doi: 10.1016/0168-1591(91)90262-V

Swets, J. A. (1988). Measuring the accuracy of diagnostic systems. Science 240, 1285-1293. doi: 10.1126/science.3287615

Thuiller, W. (2007). Climate change and the ecologist. Nature 448, 550-552. doi: $10.1038 / 448550$ a

Thuiller, W., Broennimann, O., Hughes, G., Alkemade, J. R. M., Midgley, G. F., and Corsi, F. (2006). Vulnerability of African mammals to anthropogenic climate change under conservative land transformation assumptions. Glob. Change Biol. 12, 424-440. doi: 10.1111/j.1365-2486.2006.01115.x

Thuiller, W., Lavorel, S., Araújo, M. B., Sykes, M. T., and Prentice, I. C. (2005). Climate change threats to plant diversity in Europe. Proc. Natl. Acad. Sci. U.S.A. 102, 8245-8250. doi: 10.1073/pnas.0409902102

Vollering, J., Halvorsen, R., Auestad, I., and Rydgren, K. (2019a). Bunching up the background betters bias in species distribution models. Ecography 42, 1717-1727. doi: 10.1111/ecog.04503

Vollering, J., Halvorsen, R., and Mazzoni, S. (2019b). The MIAmaxent R package: Variable transformation and model selection for species distribution models. Ecol. Evol. 9, 12051-12068. doi: 10.1002/ece3.5654 
Watson, J. E., Dudley, N., Segan, D. B., and Hockings, M. (2014). The performance and potential of protected areas. Nature 515, 67-73. doi: 10.1038/nature13947

Williams, D., Clark, M., Buchanan, G., Ficetola, G. F., Rondinini, C., and Tilman, D. (2021). Proactive conservation to prevent habitat losses to agricultural expansion. Nat. Sustain. 4, 314-322. doi: 10.1038/s41893-020-00656-5

Wood, S. N. (2011). Fast stable restricted maximum likelihood and marginal likelihood estimation of semiparametric generalized linear models. J. R. Stat. Soc. Ser. B Stat. Methodol. 73, 3-36. doi: 10.1111/j.1467-9868.2010.00749.x

Zielinski, W. J., Carroll, C., and Dunk, J. R. (2006). Using landscape suitability models to reconcile conservation planning for two key forest predators. Biol. Conserv. 133, 409-430. doi: 10.1016/j.biocon.2006.07.003
Conflict of Interest: The authors declare that the research was conducted in the absence of any commercial or financial relationships that could be construed as a potential conflict of interest.

Copyright $\odot 2021$ Gebremedhin, Chala, Flagstad, Bekele, Bakkestuen, van Moorter, Ficetola, Zimmermann, Brochmann and Stenseth. This is an open-access article distributed under the terms of the Creative Commons Attribution License (CC BY). The use, distribution or reproduction in other forums is permitted, provided the original author(s) and the copyright owner(s) are credited and that the original publication in this journal is cited, in accordance with accepted academic practice. No use, distribution or reproduction is permitted which does not comply with these terms. 